\title{
The IEEE Pathfinder on Power and Energy: A Living Document for Selecting and Filtering Web-based Resources
}

\author{
Peter Wiesner, Mary Jane Miller \\ IEEE Corporate Strategies and Communications/IEEE Operations- \\ Library \\ Noel N. Schulz \\ Electrical \& Computer Engineering, Mississippi State University \\ Karen Miu \\ Electrical and Computer Engineering, Drexel University
}

\begin{abstract}
IEEE obtained a small grant from the National Science Foundation to identify and make accessible tutorial materials that would help students and the public to understand the basics about power and energy. Although many excellent resources on power and energy are available on the Web, users lack access to online tools to discover vetted resources on the Internet. This paper makes a case for developing "pathfinders" to help engineering students and other users navigate the Web for technical resources. It describes the completed IEEE Pathfinder on Power and Energy and IEEE's use of content management tools to enable IEEE volunteers from the IEEE Power Engineering Society to maintain it.

\section{"Water, water everywhere but not a drop to drink"}

The quest of finding information in the sea of data can be fraught with challenges even for knowledgeable users. A search may yield interesting results, but what information is available concerning the quality and credibility of data? Is there a credible vetting process for pointing to what is important and relevant for students?

Since the August 2003 Blackout in the Northeast, the Web has provided abundant technical information related to electric power systems and blackouts. But what is really needed by the general public is a readily accessible explanation of how power is generated and distributed. Professionals outside of engineering need quick introductions to technical problems and issues pertaining to policy matters related to power and energy. Although the Internet leads users to valuable resources quickly, there is a need to filter the vast amount of information available online.
\end{abstract}


Part of the problem is the fast growth of the Internet and the lack of tools to cope with it. Powerful search engines yielded thousands of "hits" in response to key terms, but the results are invariably mixed and difficult to evaluate. Some sites provide useful links, but often these are not annotated and updated and so their usefulness is limited. Because many users lack the perspective and context to select the proper key terms when searching for technical information on the Web, excellent resources within web sites need to be recommended in order to be found.

For example, the term, "electric power" first yields the following sites through Google: EPRI, American Electric Power, World Electric Power Guide, sciencedirect.com, Electricity Around the World, TEPCO, Pepco Corporate Web Site Homepage, Electric Power Supply Association, Solar Electric Power Association, and Tucson Electric Power Company. While some of these provide excellent information, the uninformed user has no frame of reference for evaluating the quality or relevance of the information.

Recognizing the need to categorize and contextualize information, the IEEE Power Engineering Society, ${ }^{1}$ in cooperation with IEEE Educational Activities, developed the Pathfinder on Power and Energy ${ }^{2}$ with funding from the National Science Foundation. The term "pathfinder" is commonly used in the library world to provide users with a quick way of finding resources. ${ }^{3}$ Pathfinders are more informal than annotated bibliographies that are scholarly in nature. Research organizations, such as Lucent, use pathfinders in the form of handy lists of brief annotated resources in particular subject areas.

Building on traditional librarianship, IEEE developed this pathfinder to vet resources on power and energy that are already available through the Web. This tool provides a functional organization for a rudimentary search and focuses on a small number of wellestablished sites open to the public, which include tutorial materials and provide information, data, and links to other resources.

The initial idea of the NSF-funded project was to develop a guide that would include tutorials materials on power and energy. But it soon became obvious the Internet provides access to useful information, including tutorials. It became clear that the real task is to develop a reference tool that would quickly bring users to resources from trusted sources. This tool, the Pathfinder on Power and energy, was to be more than a page with links. It would organize and vet a set of annotated links with input from experts in the power and energy field.

To develop the Pathfinder, the project staff worked with engineering educators to develop a scheme for organizing the power and energy resources on the Web could be immediately useful to both the technical and non-technical user. This was a timeconsuming process. However, the project staff realized that the real challenge in creating useful pathfinders is in sustaining them after the initial enthusiasm of their creation wanes. All too often, resources on the Internet tend to be ephemeral because there are no staff or volunteers committed to maintaining and updating content. This led to the use of 
a content management system, described later in this paper, which allows volunteers to create and maintain Web content easily.

\section{Education and Information--the Larger Issues}

The Pathfinder project focused largely on the needs of uninitiated users. But the need to vet information on the Web also extends to engineering students and other users who are relatively knowledgeable about technology.

Universities play an important role in guiding the selection and evaluation of the resources used by students. In addition to being repositories of information, university libraries also engage in scholarship to add value to their collections. Students who use the Web often circumvent libraries by conducting undiscriminating online searches and thereby lose the benefit of the library's scholarship and expertise. According to one educator, "It's all about content.... The library is really good at vetting and organizing published content, while the educational-technology groups work with faculty with their unpublished content. And yet students need both at their fingertips. We don't want them just going to 'Google'."4

The ability to find and evaluate information is important for both engineering student and graduate engineer who make extensive use of the Web to access to vast databases and digital libraries. Both depend heavily on search engines to discover and locate materials. and mostly fend for themselves without the help of librarians and other information specialists.

Many university libraries, such as the University of Wisconsin at Madison, provide online instructions on how to use online collections of their library web sites. ${ }^{5}$ However these provide no insight into to the scholarly work that underlies the process for selecting resources. Engineers can benefit from further guidance even when using powerful online libraries such as IEEE's Xplore ${ }^{6}$ that provide users with advanced search capabilities to download materials. Browsing the vast IEEE database can be daunting and timeconsuming even for experienced user. Certainly, for the non-technical person, not knowing relevant vocabulary and basic contextual information is a major barrier to conduct effective key-term searches. Even engineers familiar with one field must learn the key terms and their context for mounting a fruitful search for materials in another field.

The need to provide aids in searching for information is recognized by commercial publishers. For example, Elsevier offers end-user assistance through E-Village 2 in the form of "ask a librarian" and "ask an engineer." 7 Efforts are being made to provide a library-like environment on the Web. The federally funded AskERIC at Syracuse University is a personalized Internet-based service providing information about education to educators. The AskERIC Question Archive makes use of information specialists to answer questions regarding resources that may include ERIC citations, Internet sites, discussion groups, and/or print resource information. ${ }^{8}$ 
The University of Wisconsin Internet Scout Report is one of the Internet's longestrunning weekly publications. It offers a selection of new and newly discovered online resources of interest to researchers and educators. Among many reports, there are three bi-weekly reports on a selection of online science, math, and engineering and technology resources. ${ }^{9}$ The Scout Reports provide an excellent example of filtering sites on the Web through a review process. One drawback of the Scout Reports is that they are issued once and not updated.

Another approach to vetting websites is provided by an organization called Fields of Knowledge, which claims that "...robotic keyword searches, popularity gauges, in-house geeks, paid rankings in search-engine results, and by-chance browsing have gained alarming leverage upon students' search for knowledge." This organization urges that professors and other accredited scholars must vet knowledge and asserts that academic authority is being usurped by "technonauts." 10 Fields of Knowledge provides a Webbased industry-sponsored service called Infography that invites professors, librarians, and other research scholars to write short research tools for publication citing the superlative and excellent sources of information about their subjects of expertise. This process is labor-intensive and depends on submissions by content experts who may or may not be paid.

The labor-intensive approach tends not to fit well within a volunteer structure. Although IEEE volunteers provide many services in support of IEEE publications and professional activities, there may not be sufficient incentives for IEEE volunteers to spend a lot of time to vet information sources for students and members of the public. For that reason, the IEEE pathfinder's scope and approach, as described below, is scaled to entice volunteer involvement.

\section{The Pathfinder Project}

Partially funded by the U.S. National Science Foundation, the Pathfinder Project is intended to help users find authoritative information on power and energy by

- Leading users to selected Web sites on the Internet

- Providing concise descriptions of these sites

- Assuring quality control through an IEEE peer-review process

- Providing a mechanism for enabling new sites to be nominated for inclusion

Work on Version 1 of the Pathfinder involved input from engineering librarians, including the IEEE's Mary Jane Miller, as well as from engineering faculty, including Karen Miu of Drexel University and Noel Schulz of Mississippi State University, assisted by Derrick Cherry, a graduate student in engineering. Peter Wiesner, IEEE Educational Activities, managed the project as its Principal Investigator. Library science and engineering students from Rutgers and Mississippi State contributed intellectually to the project. 
The Pathfinder on Power and Energy provides annotated links to relevant resources on the Web for those interested in the electric power and energy field in both the United States and other countries. It steers users to a limited number of sites that are likely to contain resources for an expanded search. Like a travel guide, its aim is to organize and highlight resources but not to overwhelm the user. This pathfinder introduces and evaluates the most reliable sources of information in the field of power and energy. Like all guides, it is limited in scope and only provides a beginning for the journey.

The intended users of the IEEE Pathfinder on Power and Energy are members of the general public, including professionals outside of engineering, who need a readily available introduction to reliable Web-based information resources in power and energy. Engineering students will also find it useful as a quick reference. The Pathfinder also provides pre-college teachers and students a section that links to resources in support of class activities and general learning. When the Pathfinder is published, there will be links to it from the home page of the IEEE Power Engineering Society and the IEEE Virtual Community on Power and Energy. There will also be links from IEEE Educational Activities.

\section{Selection Criteria}

The first version of the Pathfinder is populated with Web sites that are generally known to be reliable and well maintained, particularly those of large governmental agencies, such as the U.S. Department of Energy. The Pathfinder includes the category "Major Public Sites," which lists publicly available national information resources in the United States and Canada, Europe, and Asia. These include large non-government agencies as well as governmental agencies. It is impractical to organize national sites by country because of the uneven availability of such resources across the globe. The category "International Perspectives" includes sites that focus on the international aspects of power and energy and that also link to national sites.

The "Pathfinder" also includes categories for specific topics of potential interest to students and lay users, such as "Alternate Energy Resources," "Environmental Issues, Sustainability, and Conservation," "Regulation and Deregulation," and "Power Quality and Reliability." Since the "Pathfinder" is primarily intended for students and nonspecialists, it includes educational resources, such as tutorials on energy and electricity. The categories can be modified as the need arises.

Since a pathfinder is an evolving document, its organization and content are subject to review and change. Version 1 is really intended to encourage teachers, librarians, and other stakeholders to join the IEEE in providing the public with a coherent approach to the great volume of information that is available. ${ }^{11}$ Other than annotations, the IEEE Pathfinder does not include original content. Its chief purpose is to steer users to resources. It is more than merely a links page, however, as each vetted site is annotated to indicate its quality and usefulness. 
Table 1- Examples of Pathfinder Entries

\section{Future Energy Solutions - RESTATS \\ http://www.etsu.com/RESTATS \\ Presents the results of an ongoing study undertaken by Future Energy Solutions (part of AEA Technology - AEAT Environment) on behalf of the Department of Trade and Industry, to update a database containing information on all relevant renewable energy sources in the United Kingdom. This database is called RESTATS, the Renewable Energy STATisticS database.}

\section{International Energy Agency (IEA)}

http://www.iea.org/

The IEA is an energy forum with 26 member countries. IEA member governments are committed to taking joint measures to meet oil supply emergencies. They have also agreed to share energy information, to coordinate their energy policies and to cooperate in the development of rational energy programs. This site includes links to member countries and non-member countries. It also provides many links to publications and statistics relating to oil, energy management, energy technology, renewable energy, and energy efficiency.

\section{Organization of the Pathfinder}

The look and feel of the IEEE Pathfinder conforms to the design of the IEEE Web site. The left menu bar, indicated below, leads to pages with annotated links. The menu bar immediately on top takes the user to pages that explain the purpose of the site and ways to submit content. At the very top is the standard IEEE menu bar. Version 1 of the Pathfinder includes 350 sites organized under eleven categories:

- International Perspectives (33)

- Major Resources on energy and Power (31)

- Associations (48)

- Regulation and Deregulation (21)

- Education and Careers (20)

- Publishers and Databases (27)

- Conferences (30)

- Environmental Issues, Conservation, and Sustainability (41)

- Glossaries (28)

- Sites for Students and Teachers (36)

- Sites with Links (31)

- Communities and Discussion Groups (12)

- Power Quality and Reliability (12)

- Alternate Energy Resources (7) 
The number of sites on the Pathfinder may increase, but it should not exceed 500. The idea is to provide users with a selected number of sites, not to overwhelm them. Annotations are kept concise for that reason. Also the topics will be kept to a manageable number.

Table 2-Screen Shot of Pathfinder

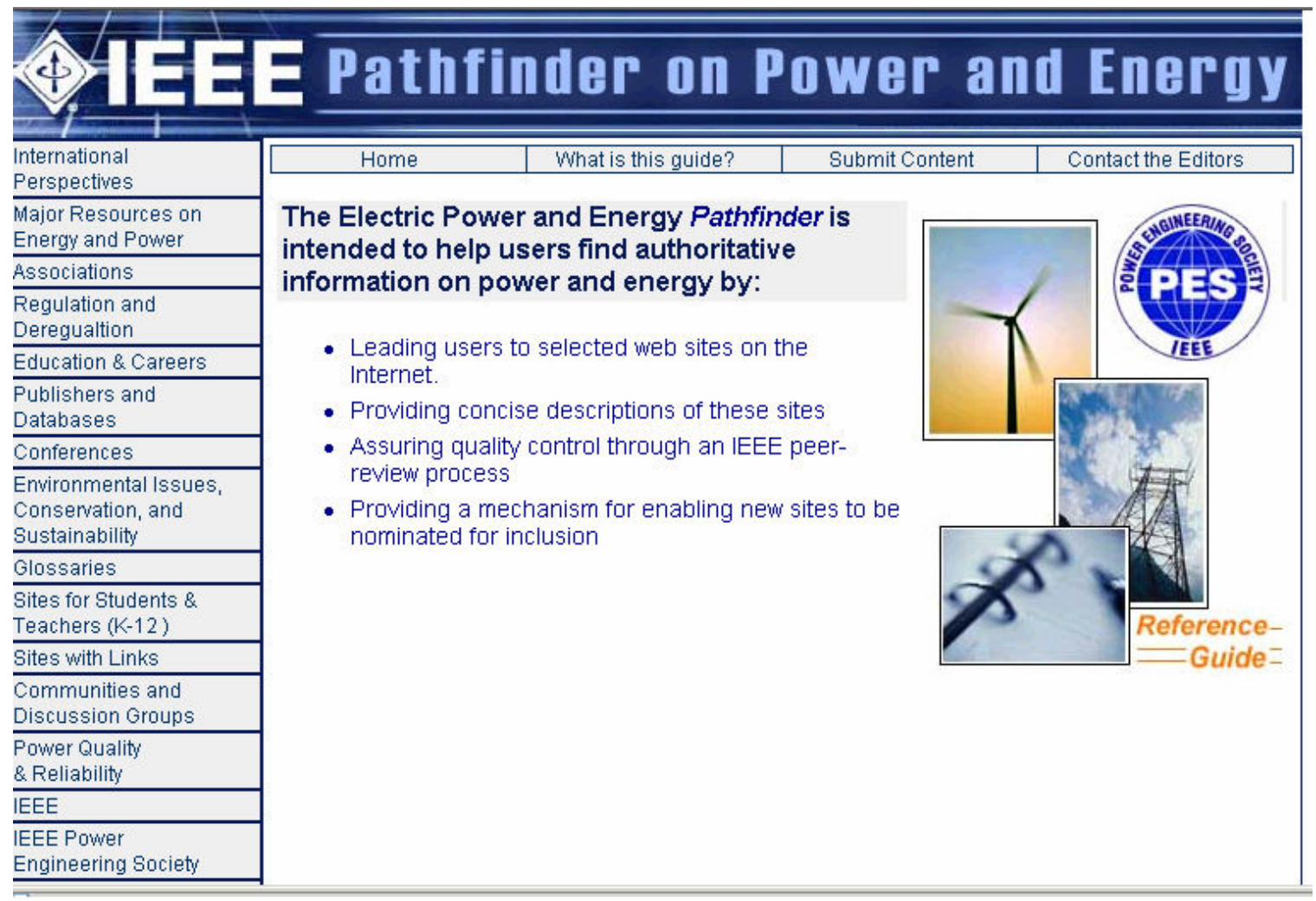

\section{Review and Maintenance}

Maintainability is an integral part of the design of this pathfinder, whose scope and organization have deliberately been kept simple.

IEEE's approach to sustainability is to engage the volunteers in the Power Engineering Society who are responsible for outreach. Maintaining the pathfinder is one way for volunteers to meet their professional obligation to be of service to a broad public. Some volunteers are educators who believe that this tool would be useful to their engineering students. Volunteers from industry may be motivated to inform the general public about issues and data in their areas of endeavor.

The IEEE recognizes that there must be an organizational framework to facilitate sustainability since volunteers serve for limited periods of time. There must be continuity as various volunteers assume responsibility for vetting pathfinder sites. For that reason, the Power Engineering Society has assigned the pathfinder project to the Power Engineering Promotion Subcommittee of the PES Education Committee (PEEC). ${ }^{12}$ 
Assigning ownership is only one step. Since volunteer time is limited, the process for maintenance must be streamlined so that the mechanics of updating Web sites does not become a barrier. One solution is to use a content management system that allows individuals to create or alter web pages without knowledge of HTML. Such systems enable volunteers to create and modify content for the Web simply by applying word processing knowledge. Content management allows users to manage specific content without affecting an entire Web page and requires little or no HTML skills are required to write and upload content to Web pages. A Web browser is used to gain access with authentication. This system includes a $\mathrm{Q} / \mathrm{A}$ process that documents release or rejection with email to the content owner/editor.

Fortunately, IEEE has already embarked on a major initiative to deploy content management to empower both its staff and volunteers to create and maintain content for the Web. The IEEE Power Engineering Society is one of the first IEEE Societies to use a content management system to enable its volunteers to create content for their Society's web site. Assigned subcommittee ownership and easy access to content management should form a good foundation for the Pathfinder.

The IEEE Pathfinder on Power and Energy will be reviewed annually. This level of effort is appropriate given the availability of volunteer time for projects of this nature.

Maintaining the pathfinder would provide an opportunity for volunteers to serve their profession, which includes outreach to the public on technology matters. It is expected that IEEE volunteers will be motivated to maintain the "Pathfinder on Power and Energy" if there is positive feedback from users.

Whether or not volunteers will maintain the Pathfinder on Power and Energy remains to be seen. Another approach for maintaining content would be to engage academic librarians who have professional reasons for authoring and maintaining pathfinders and other Web tools. The IEEE will explore this option, matching up engineers and librarians in the academic world, as it moves ahead with the creation of pathfinders in other engineering areas.

\section{Looking Ahead}

This project points to a trend of developing tools that are specifically designed to sift through the large quantities of information sources unearthed through search engines. Professional information specialists and librarians, who have succeeded in melding traditional librarianship with the Web, will develop more of these kinds of tools and other accredited scholars

The "Pathfinder on Power and Energy" is limited to Web sites. Other pathfinders will be needed to help engineers "drill down" for more detailed information on power and other fields. For example, there might be a pathfinder focusing specifically on power quality and security, or on alternate energy. Once the scope is narrowed, the pathfinder will lead users to specific publications and key scholarly works that may be available through Web 
sites and databases. But again, the scope must be limited to keep it manageable for the user as well as the owner. Pathfinders are only useful to provide users with a good start based on the selection of key resources by qualified professionals. Once users are oriented, they are equipped to use search engines that are becoming increasingly more sophisticated.

In the future, users will have numerous Web-based information tools at their disposal. A common look and feel would be helpful to minimize the time needed to become familiar with new tools. The credibility of such tools will be a central issue.

For engineering, the challenge is to develop a taxonomy that will enable users to select their path in a broader disciplinary and applications context. This is not as simple as it sounds. Engineering is a complex area consisting of many fields, sub-disciplines, and application areas. The increasing interdisciplinary nature of engineering brings it in contact with the physical and social sciences and the humanities.

For example, the field of electrical engineering is extremely broad, with many, often overlapping sub-disciplines. As of March 2004, the IEEE recognizes thirty-eight Technical Societies and four Technical Councils as wide ranging as Geoscience and Remote Sensing, Environment Health and Safety, Magnetics, and Computers. ${ }^{13}$ However, even this partitioning is somewhat arbitrary. For example, the IEEE uses several hundred Technical Interest Profiles (TIP) codes, which are a list or grouping of technical areas identified by IEEE Societies and Councils. These correlate to the breadth and scope encompassed by each of the IEEE organization's technical interests.

Certainly, for outsiders, the engineering field is complex. For the technically active insider, there may be relative calm within his/her discipline area, but once insiders step outside their fields, they too encounter some of the problems of the technically uninitiated. Then they too can benefit from tutorials that provide orientation and overviews. But there are limits to the effectiveness of this strategy too. Tools that clarify knowledge infrastructures are really heuristic, given the dynamic nature of engineering and other creative fields

Although it is inherently difficult to categorize emerging fields, there are many established areas in engineering where definition and clarity are greatly needed, especially where the public interest and technical developments intersect. Power and energy is just one of these. A pathfinder may only be able to provide a partial set of sources for beginning queries. In technical areas, users may need tutorials for orientation and to fill gaps of knowledge needed to mine sources.

The Power Engineering Society offers instructor-led sessions on power and energy basics at its conferences and plans to continue and possibly expand this effort, perhaps online. Tutorials targeted at a specific audience (including students, the general public, and regulators) could be effectively coordinated with online reference material, including those contained in pathfinders. For the IEEE, Web-based tutorials will enable engineers 
to make better use of the IEEE's digital library through IEEE Xplore, the vast database of nearly one million documents.

The significance of the IEEE Pathfinder Project is that it reintroduces traditional librarian concepts to an engineering community that has come to expect a lot from search engines. Although search engines will become increasingly effective, human beings still play an important role - especially at the beginning stages of knowledge acquisition — in vetting the reliability and importance of information sources.

The actual construction of the "Pathfinder" was a relatively simple and straightforward task. However, it makes an important contribution by pointing out the need for tools currently not available on the Web. These tools will enable users to discover, explore, and evaluate highly specific technical information sources.

Information, after all, consists of "reducing uncertainty," as discussed by Shannon and Weaver. ${ }^{14}$ In that sense, the value of the pathfinder concept is to enable users to begin the process of finding information in the vast sea of data.

\footnotetext{
${ }^{1}$ IEEE Power Engineering Society, http://www.iee.org/portal/index.jsp?pageID=pes home

2 "IEEE Pathfinder on Power and Energy, http://www.ieee.org/pes pathfinder

3 “A Pathfinder for Constructing Pathfinders: Guides to Information Sources," http://home.wsd.wednet.edu/pathfinders/path.htm

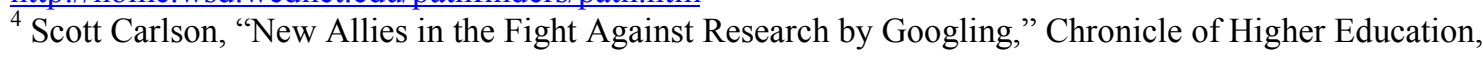
March 21, 2003

${ }^{5}$ University of Wisconsin, Madison, http://www.uwm.edu/Library/ris/guides/ieee.htm

${ }^{6}$ IEEE Xplore http://ieeexplore.ieee.org/Xplore/DynWel.jsp

${ }^{7}$ Elsevier E Village 2, http://www.engineeringvillage2.org/controller/servlet/Controller

${ }^{8}$ ERIC, http://askeric.org

${ }^{9}$ University of 'Wisconsin Internet Scout Tools, http://scout.wisc.edu/research/SPT/)

${ }^{10}$ Fields of Knowledge, http://www.fieldsofknowledge.com/specialist/subjectspecialist1.html.

${ }^{11}$ IEEE Pathfinder: Power and Energy, http://www.ieee.org/organizations/eab/refguide/default.htm

${ }^{12}$ IEEE Power Engineering Society Education Committee http://www.ieee.org/portal/index.jsp?pageID=pes_home

${ }^{13}$ IEEE Technical Interest Profiles http://www.ieee.org/organizations/pubs/press/Technical_Interests.htm

${ }^{14}$ Shannon, C.E., \& Weaver, W. (1949), The Mathematical Theory of Communication. Urbana: University of Illinois Press
}

NOEL N. SCHULZ is Associate Professor of Electrical \& Computer Engineering and Director of the Women in Engineering and Faculty Development at Mississippi State University. She was on the faculty of Virginia Tech, the University of North Dakota, and Michigan Technological University. She is actively involved in the IEEE Power Engineering Society as well as ASEE.

MARY JANE MILLER is IEEE Corporate Librarian. She holds a Masters of Science in Library Science from the University of North Carolina at Chapel Hill and a Bachelor of Arts in English from Berea College, 
Berea, KY. Prior to joining IEEE, she managed libraries in R\&D organizations of two Fortune 500 companies.

KAREN NAN MIU is Assistant Professor of Electrical Engineering at Drexel University. She received the B.S, M.S. and Ph.D. degrees in Electrical Engineering from Cornell University. As recipient of the NSF Career Award and the ONR Young Investigator Award, she has applied this support to develop hardware and software educational laboratories and participate in sustained K-12 outreach programs at Drexel.

PETER K. WIESNER has been a staff member at IEEE since 1989. Formerly Director of Continuing Education, he is currently with IEEE Corporate Strategies and Communications. He has been involved in several projects funded by NSF and by the Sloan Foundation. He holds a Bachelor's in History from UC Berkeley, a Master's in Communication from University of Pennsylvania and an Ed.D. from Rutgers. 